\title{
Tecnologia Assistiva: a inserção de aplicativos de tradução na promoção de uma melhor comunicação entre surdos e ouvintes
}

\author{
Ygor Corrêa - PPGIE/UFRGS, y.correa@bol.com.br \\ Maristela Compagnoni Vieira, PPGIE/UFRGS, maricompagnoni@gmail.com \\ Lucila Maria Costi Santarosa, PPGIE/UFRGS, lucila.santarosa@ufrgs.br, \\ Maria Cristina Villanova Biasuz,PPGIE/UFRGS, mcbiazus@ufrgs.br
}

Resumo: Este artigo apresenta os aplicativos HandTalk e ProDeaf, ambos tradutores de Língua Portuguesa, oral e escrita, para a Língua Brasileira de Sinais (Libras). Deste modo, descrevemos suas especificidades operacionais, enquanto mediadores inclusivos de processos comunicacionais. Nesta perspectiva, o estudo é composto por narrativas de indivíduos surdos e ouvintes, oriundas de um curso de formação continuada de professores, cuja análise de conteúdo permitiu identificar a emergência de potencialidades e fragilidades dos aplicativos. Os resultados obtidos revelaram o potencial inclusivo das ferramentas analisadas, nos âmbitos escolar e social, em aspectos como: interação, ampliação de vocabulário, constituição identitária e autonomia do sujeito surdo.

Palavras-Chave: Libras, Tradução Automática, Inclusão Social, Pessoas Surdas.

Accessible Technology: The insertion of translation apps in the promotion of a better communication between deaf and hearing people

Abstract: This article presents HandTalk and ProDeaf apps, both translators of Portuguese, oral and written, to Brazilian Sign Language (Libras). Therefore, we describe their operational specificities as inclusive mediators of communicational processes. In this perspective, the study consists of narratives of deaf and hearing individuals, originated from a teachers training course, whose content analysis allowed us to identify the emergence of potentialities and fragilities of these apps. The results revealed the inclusive potential of the analyzed tools in the social and school contexts, in aspects such as: interaction, vocabulary building promotion of identity constitution and autonomy of the deaf individual.

Keywords: Brazilian Sign Language, Automatic Translation, Social Inclusion, Deaf People.

\section{INTRODUÇÃO}

A base epistemológica deste estudo enquadra-se aos pressupostos teóricos de Vygotsky (2010), nos quais a linguagem, e sobretudo, a fala desempenham um papel fundamental no desenvolvimento das funções psicológicas superiores, como a memória, a percepção e a atenção. Para além do desenvolvimento dessas funções, é também por meio da linguagem e da língua, que ocorrem os processos de socialização - elemento fundamental da constituição humana, inerentemente associado aos processos de interação. Para Vygotsky (2010), a mediação é uma característica da cognição humana, que se refere à internalização de atividades e comportamentos, incluindo ouso de ferramentas e de signos. A combinação do uso desses instrumentos possibilita o desenvolvimento dos processos psicológicos superiores, ou seja, do social (inter) para o individual (intra) por meio da internalização desses. (Werstch, 1988). Embora exista uma variedade de ferramentas psicológicas capazes de mediar a atividade humana, as interações e mediações sociais ocorrem, principalmente, por meio da linguagem oral e escrita. Neste tocante, as escolas inclusivas visam a promoção da educação em espaços educativos comuns a todos, dentre os quais estão inseridas as pessoas surdas, que se 
comunicam por meio de uma língua gestual-visual chamada de Língua Brasileira de Sinais - Libras (Quadros, 2003). Assim, ao considerar que barreiras na comunicação podem resultar em processos de interação deficitários e contribuir para a segregação social (Warschauer, 2006), a comunidade escolar deparou-se com o desafio da presença de uma formação bilíngue para possibilitar mediações significativas, tanto para surdos quanto para ouvintes.

O processo que exclui a pessoa surda em virtude das diferenças linguísticas é reproduzido na escola quando não há entre os estudantes, sujeitos que se comuniquem por meio da Libras. De acordo com Vygotsky (2010, p.58) "todas as funções superiores originam-se das relações reais entre indivíduos humanos”. Logo, a pessoa surda, inserida em um contexto social escolar de ouvintes que não sinalizam, não transforma, naturalmente, um processo interpessoal em intrapessoal, dada a ausência de interações com pares capazes de estabelecer com ela uma comunicação entendida como significativa para seu desenvolvimento cognitivo.

Diante dos desafios da escola inclusiva, surgem cursos de capacitação de professores da rede educacional pública, que propõem o desenvolvimento de estratégias de mediação que permitam superar desigualdades e minimizar processos de exclusão, de modo a proporcionar maior autonomia às pessoas com deficiência (Santarosa e Conforto, 2012, p. 13). É o caso do Curso de Formação Continuada de Professores em Tecnologias de Informação e Comunicação Acessíveis do Núcleo de Informática na Educação Especial (NIEE) da Universidade Federal do Rio Grande do Sul (UFRGS) no qual são exploradas ferramentas da ordem das Tecnologias Assistivas (TAs) (Cook e Hussey, 1995), capazes de mediar as relações do sujeito que apresenta alguma incapacidade ou desvantagem com o mundo físico e social.

Concernente à contextualização realizada, este estudo tem por objetivo discutir as potencialidades e fragilidades de dois aplicativos, ProDeaf e HandTalk, que realizam tradução automática da Língua Portuguesa para Libras - ferramentas de mediação para a comunicação entre sujeitos surdos e ouvintes - na perspectiva dos sujeitos envolvidos no curso supracitado e descrito na seção 3.

Neste tocante, investiga-se aspectos dessas ferramentas como: a) o potencial inclusivo; b) possíveis aprimoramentos linguísticos para os usuários; c) usabilidade; e d)potencial na promoção da autonomia e da subjetivação do sujeito surdo.

Este artigo está dividido nas seguintes seções: 1 Introdução; 2 A inclusão da pessoa surda mediada pela tecnologia - um breve referencial teórico da área, onde são apresentados os aplicativos ProDeaf e HandTalk; 3 Metodologia - onde apresentamos a técnica de análise dos dados, bem como a população envolvida e o contexto da mesma; 4 Análise dos dados e 5 Elucidações sobre a dinâmica dos aplicativos. Ao finalno item 6 são apresentas as Considerações Finais.

\section{A INCLUSÃO DA PESSOA SURDA MEDIADA PELA TECNOLOGIA}

Esta seção tem como prerrogativa apresentar a perspectiva inclusiva acerca do sujeito surdo, seguida da descrição de dois aplicativos de tradução de Língua Portuguesa para Libras. Embora a proposta educacional inclusiva, no que tange à pessoa surda, seja a do bilinguismo (Brasil, 2008), há escolas comuns que ainda não apresentam estrutura capaz de permitir ao surdo interações sociais efetivas por meio de sua língua materna (Quadros, 2003). Concernente a isso, Vygotsky (2010) aponta como deficiente o contexto social que não atende à demanda do sujeito que apresenta alguma alteração biológica frente as suas necessidades cotidianas. Assim, não é a alteração biológica, enquanto deficiência, que se mostra restritiva, mas a inequidade das estruturas sociais. 
Para Quadros (2003) o contexto social que favorece a pessoa surda é aquele em que ela se realiza plenamente em suas interações linguísticas.

Enquanto espaço de socialização e desenvolvimento, a escola deve proporcionar a realização de processos de construção da autonomia e da subjetivação, os quais configuram-se como processos que constituem os sujeitos. Segundo Touraine (2009) e Bakhtin (1990) é no processo de subjetivação que ocorre a construção, por parte do indivíduo ou do grupo, de si mesmo enquanto sujeito. Nessa perspectiva, a problematização das representações sociais ajuda a romper a barreira dos preconceitos e estabelece novas estruturas interacionais. Inserir a pessoa surda via tecnologia pode ser uma das formas de promover a interação, comunicação e subjetivação do sujeito. Desta forma, visando corroborar o papel das tecnologias na vida e na constituição dos sujeitos, este estudo apoia-se em uma inferência de Lévy (2000, p.84), que afirma:

(...) não basta estar na frente da tela de um computador, munido de todas as interfaces amigáveis que se possa pensar, para superar uma situação de inferioridade. É preciso antes de mais nada estar em condições de participar ativamente dos processos de inteligência coletiva, (pois) a luta contra as desigualdades e a exclusão deve visar o ganho de autonomia das pessoas ou dos grupos envolvidos (grifos do autor).

Assim, este estudo parte da premissa de que toda a atividade humana é mediada por ferramentas, sendo essas gradualmente incorporadas e que, por sua vez, alteram as práticas interacionais. Para isso, compreende-se, segundo Warschauer (2006, p.153), que "as ferramentas não penas facilitam a ação que poderia ter ocorrido sem elas, mas, ao serem incluídas no processo comportamental, alteram o fluxo e a estrutura das funções mentais" como é o caso de pessoas surdas. Ainda na ótica Vygotskyana, adotase o conceito de Nível de Desenvolvimento Real (NDR), no qual encontram-se os saberes e vivências prévias do sujeito que, neste estudo, a priori, antecedem o uso dos aplicativos analisados, mas ao serem incorporados à utilização de uma ferramenta tecnológica podem enriquecer os processos interacionais. Desta maneira, esses podem realizar o andaimento (Vygotsky, 2010) dos processos de desenvolvimento humano, logo, de aprendizagem, movendo os saberes do sujeito para a Zona de Desenvolvimento Proximal (ZDP). Portanto, é na ZDP que compreende-se que o desenvolvimento das capacidades cognitivas, por meio de interações significativas, pode ocasionar a aprendizagem de novos conhecimentos ou, então aprimorar os já existentes.

$\mathrm{Na}$ busca por tecnologias asssistivas potencialmente mediadoras da construção do conhecimento, da subjetivação e da autonomia, identificou-se no ano de 2013, o surgimento no mercado brasileiro de aplicativos para dispositivos móveis, de duas importantes ferramentas, ambas voltadas para a inclusão social: ProDeaf e HandTalk. Esses aplicativos são gratuitos e realizam traduções automáticas de palavras, termos e pequenas frases da Língua Portuguesa para Libras, por meio de um avatar animado. Ambos foram originados a partir de pesquisas realizadas em universidades do nordeste brasileiro - Universidade Federal de Pernambuco (ProDeaf) e Universidade Federal do Alagoas (HandTalk). A fim de estabelecer um panorama das características constitutivas de cada um, realizou-se uma análise operacional entre as duas ferramentas (conforme tabela 1).

Tabela 1. Características das ferramentas ProDeaf e HandTalk

\begin{tabular}{|l|l|l|}
\cline { 2 - 3 } \multicolumn{1}{c|}{} & ProDeaf & HandTalk \\
\hline Disponível para Android & SIM & SIM \\
\hline Disponível para IOS & SIM & SIM \\
\hline
\end{tabular}




\begin{tabular}{|l|l|l|}
\hline Disponível para Windows Phone 8 & SIM & NÃO \\
\hline Traduz Língua Portuguesa para Libras a partir da entrada de texto & SIM & SIM \\
\hline Traduz Língua Portuguesa para Libras a partir da entrada de voz & SIM & SIM \\
\hline Traduz Língua Portuguesa para Libras a partir da entrada de fotografias de textos & NÃO & SIM \\
\hline Disponibiliza dicionário de sinais & SIM & NÃO \\
\hline Funciona sem necessidade de acesso à Internet no momento da utilização & SIM $^{1}$ & NÃO \\
\hline É possível girar o personagem para visualizar o sinal em diferentes ângulos. & NÃO & SIM \\
\hline Permite fácil notificação acerca de algum erro identificado na sinalização. & SIM & NÃO \\
\hline
\end{tabular}

Tendo apresentado as características que compõem os dois aplicativos, passa-se à descrição da metodologia, bem como a caracterização do espaço de coleta de dados e dos sujeitos da pesquisa.

\section{METODOLOGIA}

Esta é uma pesquisa qualitativa (Moraes, 2003) que tem por objetivo investigar a utilização dos aplicativos HandTalk e ProDeaf na perspectiva sociointeracionista (Vygotsky, 2010). Ao entender que tal abordagem concebe o fator social como o cerne do desenvolvimento e da aprendizagem, justifica-se o interesse pela relação dialógica (Bakhtin, 1990) constituída entre sujeitos surdos e ouvintes, tendo como mediador um tipo de processo inclusivo possibilitado pela Tecnologia Assistiva.

Os sujeitos deste estudo participaram Curso de Formação Continuada de Professores em Tecnologias de Informação e Comunicação Acessíveis do NIEE/UFRGS, que é oferecido gratuitamente a professores da educação básica que atuam em escolas públicas de todo o Brasil e diversos países da América Latina, América Central e Espanha. A formação é operacionalizada a distância por meio da plataforma Teleduc e já se encontra na $17^{\mathrm{a}}$ edição, tendo atendido cerca de 8.000 professores.

Entre as propostas do curso está a utilização de TAs em atividades práticas no contexto da escola inclusiva, dentre as exploradas estão os aplicativos ProDeaf e HandTalk, cujas apreciações realizadas pelos professores, em parceria com sujeitos surdos e ouvintes, resultaram no corpus de análise deste estudo.

O objetivo geral da atividade proposta no curso era não apenas apresentar os aplicativos para os professores cursistas, mas levá-los a uma reflexão que elencasse os seguintes aspectos: a) descrição do sujeito convidado a participar da interação, b) relato da realização da atividade e c) opinião dos sujeitos com relação às potencialidades e fragilidades das ferramentas.

Relativo à técnica utilizada para análise dos dados, optou-se pela Análise de Conteúdo, conforme proposta por Moraes (2003), que permitiu a emergência de conceitos a partir da incidência de unidades de sentido presentes nos variados discursos analisados. Deste modo, o agrupamento de unidades evidentes nos variados discursos é que dá origem às categorias apresentadas neste estudo (seção 4). Ressaltamos ainda que, metodologias que envolvem técnicas de análise de conteúdo (Moraes, 2003; Bardin, 2007) apresentam a utilização de um mesmo fragmento discursivo, enquanto unidade, em mais de uma categoria. Além disso, diversas unidades emergem de um mesmo discurso. Sendo assim, os valores numéricos apresentados nos gráficos que representam as categorias (Fig. 1) podem apresentar incidências discursivas superiores ao número de sujeitos, uma vez que um discurso pode ser fragmentado em muitas unidades de sentido. Além disso, uma mesma narrativa (ou discurso) poderia apresentar a visão de mais de um sujeito.

\section{ANÁLISE}

A análise das narrativas ${ }^{2}$ permitiu identificar 133 fragmentos discursivos dos quais emergiram seis categorias, apresentadas conforme ordem de incidência: (a) ampliação do arcabouço linguístico (41\%), socialização da pessoa surda (36\%), usabilidade (8\%), 
aspectos econômicos (8\%), autonomia da pessoa surda (4\%) e conectividade (3\%). A fim de detalhar a análise, é possível observar na Fig. 1 a incidência dos aspectos positivos e negativos em cada uma das categorias.

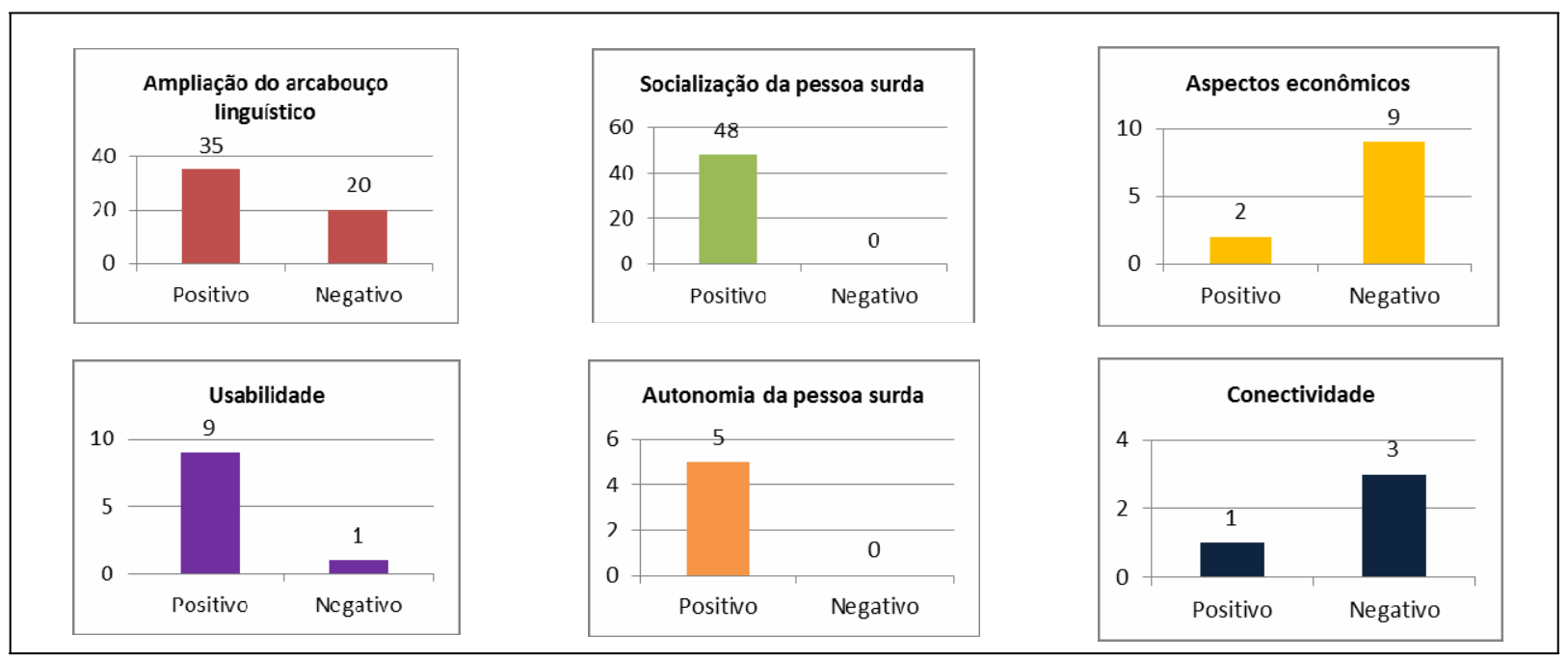

Figura 1 - Categorias conforme incidência de aspectos positivos e negativos

Após uma apresentação geral das categorias emergidas da análise e suas especificidades, passa-se a uma análise pormenorizada dessas..

\subsection{Ampliação do arcabouço linguístico}

A categoria relacionada ao conhecimento linguístico refere-se à utilização dos aplicativos como instrumentos de mediação da comunicação entre surdos e ouvintes, logo, os sujeitos perceberam que a partir da utilização desses, se faz possível a aquisição e/ou ampliação de um arcabouço linguístico referente tanto à Língua Portuguesa - para o sujeito surdo, como segunda língua, quanto à Libras, neste caso, para surdos e ouvintes.

Diversos sujeitos ouvintes enfatizaram que, ao utilizar os aplicativos, foi possível ampliar o arcabouço linguístico da Libras, por meio de consultas à ferramenta dicionário de sinais ou ainda realizando a tradução de termos escritos para sinalizados. Sujeitos surdos enfatizaram também que o aplicativo pode ser consultado, em qualquer lugar e tempo (Lévy, 2000), de modo a aprenderem vocabulário em Língua Portuguesa e não apenas quanto à incorporação de novas estruturas linguísticas em Libras.

O discurso dos sujeitos evidenciou ainda que os aplicativos em questão permitem a ampliação e a absorção e conhecimento da língua de sinais para a sociedade de maneira geral. Tal inferência fica evidente no discurso de um sujeito surdo: “(...) o aplicativo proporciona visibilidade e a concretização de uma língua àqueles que a desconhecem. Propicia sim a difusão e o interesse em conhecer a língua oficial da comunidade surda brasileira".

Percebe-se que os usos que os sujeitos ouvintes e/ou surdos fazem das ferramentas transcendem o objetivo inicial proposto por seus desenvolvedores. A aquisição de vocabulário em Português ou Libras é um exemplo. Surdos revelaram diferentes finalidades ao utilizar as ferramentas como: realizar consulta médica ou tradução de letras de músicas para Libras, elementos que serão mais amplamente discutidos na seção 4.2.

Os sujeitos ainda expressaram fragilidades ou desvantagens das ferramentas, do ponto de vista linguístico. As fragilidades apontadas pelos sujeitos foram: a presença de sinais regionalizados, típicos de regiões específicas do país; ausência do parâmetro referente à 
expressão facial no avatar, uma vez que esse é fundamental para a compreensão da Libras; traduções fora de contexto, confusas ou em desacordo com a estrutura gramatical da Libras; vocabulário de sinais restrito, o que implica na realização do português sinalizado (datilologia) e o fato de que o sujeito surdo precisa ter conhecimento básico de Língua Portuguesa para fazer uso do aplicativo, o que é um impedimento uma vez que parte dos surdos não é alfabetizada em Língua Portuguesa.

\subsection{Socialização da pessoa surda em contextos orais}

A utilização dos aplicativos como facilitadores da comunicação entre surdos e ouvintes foi amplamente mencionada pelos sujeitos como potencialidade das ferramentas (conforme tabela 2). Assim, na medida em que minimizam as barreiras linguísticas que excluem socialmente o sujeito surdo, as ferramentas contribuem para a inclusão deste na sociedade, como evidenciado em diversos depoimentos que relatam o uso dos aplicativos em situações cotidianas, tais como: gerentes de banco que utilizam a ferramenta para comunicação com clientes surdos; tradução de vocabulário Português Libras em contextos digitais como redes sociais e mensagem de texto via telefone celular; mediação da relação parental quando o surdo está inserido em uma família ouvinte; auxílio nas interações laborais do surdo com os colegas ouvintes; interação no contexto escolar seja com professores ou colegas ouvintes; na utilização de serviços públicos; consultas médicas; compreensão do conteúdo de programas televisivos; assim como para introduzir o filho ouvinte a contextos de uso da Libras.

Nenhum dos sujeitos envolvidos mencionou aspectos negativos relacionados à socialização. Tais elementos corroboram com a prerrogativa de Vygotsky (1998) para a aprendizagem: não basta um aparato biológico completamente funcional se o indivíduo não participar de ambientes e práticas específicas que propiciem seu desenvolvimento. Da mesma forma, uma defasagem sensorial pode ser compensada ou neutralizada por meio de uma TA, viabilizando assim a participação da pessoa com deficiência em ambientes e com pares capazes de proporcionar seu desenvolvimento.

Tabela 2: Impressões dos sujeitos surdos e ouvintes sobre a aplicabilidade social das ferramentas

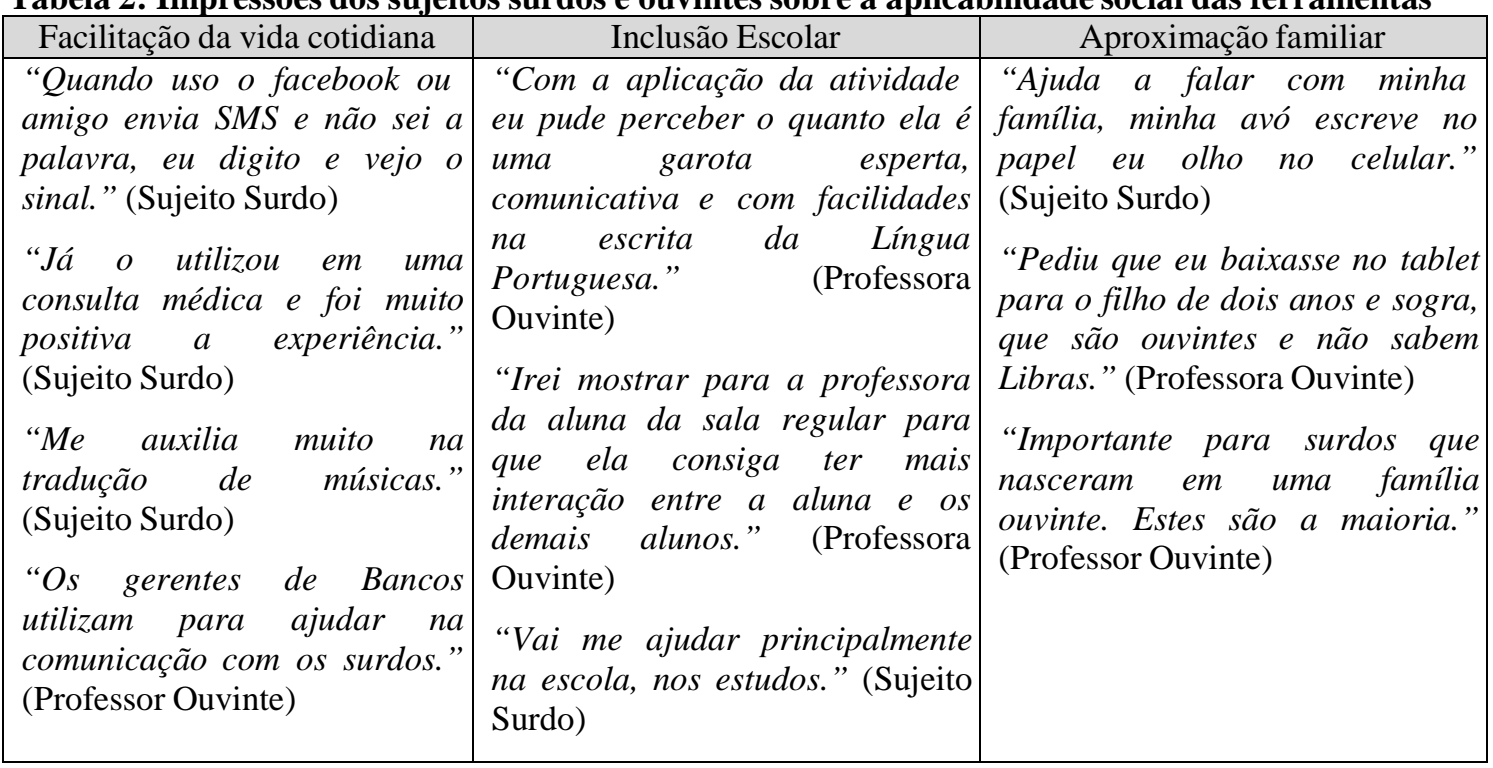

\subsection{Aspectos econômicos}

$\mathrm{O}$ acesso gratuito a ambas as ferramentas foi elencado por diferentes sujeitos como um aspecto positivo. Entretanto, do ponto de vista econômico, também foi possível observar declarações que apontavam para situações impeditivas, no que se refere à 
aquisição de um aparelho compatível com os softwares (conforme tabela 1) e o acesso à Internet móvel para a completa utilização dos recursos que constituem os aplicativos. Neste sentido, um professor ouvinte destacou, com relação ao seu aluno surdo: “(...) ele adorou o aplicativo, mas que pena que não tem aonde instalar". Nesse tocante, o fator de equidade parece ser desconsiderado devido à necessidade de que o sujeito tenha um aparelho celular smartphone. No Brasil, o preço médio de um smartphone com as configurações mínimas para acesso aos aplicativos HandTalk e ProDeaf é de cerca de $\mathrm{R} \$ 450,00^{3}$, em contraste com o salário mínimo nacional que equivale a $\mathrm{R} \$ 724,00$ (Brasil, 2013).

No que concerne às narrativas referentes aos aspectos econômicos, notou-se maior incidência de fragmentos discursivos negativos em detrimento aos positivos, sobretudo no que diz respeito ao custo dos aparelhos compatíveis com as ferramentas e dos gastos com Internet móvel. Por outro lado, entende-se que, se necessário fosse adquirir um aparelho específico para utilização destes aplicativos, talvez esse custo ainda fosse superior ao de um smartphone, já inserido no cotidiano da sociedade contemporânea digital. Além disso, um aparelho específico, caso existisse, poderia operar fora da lógica operacional-digital dos smartphones, o que implicaria na necessidade de habilidades novas e específicas para seu uso.

\subsection{Usabilidade}

De acordo com Nielsen (2003) usabilidade é um atributo de qualidade de sistemas digitais, relacionado à facilidade de aprendizado, eficiência de uso, facilidade de memorização, prevenção e tratamento de erros e nível de satisfação. Nessa perspectiva, foi possível identificar que os sujeitos evidenciaram o quão fácil é o processo de utilização de ambos os aplicativos, desde o download nas lojas virtuais à utilização. Notamos a preponderância de fragmentos positivos em relação a apenas um negativo referindo-se à necessidade de aprender a utilizar melhor o recurso de reconhecimento de caracteres em imagens (que na prática, consiste em fotografar um texto e solicitar aos aplicativos que transformem a imagem digitalizada do texto em Libras). Com relação à facilidade de uso, destacamos depoimentos como: "considero uma ótima ferramenta (...) é muito fácil de instalar e o download é grátis" (Professor Ouvinte) e "é um aplicativo muito fácil de usar, pois funciona pelo teclado ou pela voz.". (Professor Ouvinte)

Durante a análise também foi possível inferir que os sujeitos surdos ficaram impressionados com a abrangência tecnológica dos aplicativos diante da realidade comunicacional de um surdo, logo, afirmando que são de grande valia para o estabelecimento da interação entre surdos e ouvintes, como relatado por uma professor ouvinte: "Foi uma descoberta emocionante, não conheciam estes aplicativos, práticos, acessíveis, atrativos, fáceis, uma dinâmica inovadora para a sala de aula, pois, traduz a Língua Portuguesa para a Língua Brasileira de Sinais, indispensável tanto para o professor quanto para alunos surdos.”.

\subsection{Autonomia da pessoa surda}

Ao atuarem como minimizadores das barreiras comunicacionais entre surdos e ouvintes, os aplicativos contribuem para a construção da autonomia da pessoa surda, como em situações nas quais a língua escrita é preponderante, como em redes sociais e mensagens de texto no celular. A seguir, é possível observar narrativas que evidenciam outras situações: "Já utilizei [o aplicativo] em uma consulta com o médico e foi muito positiva a experiência." (Sujeito Surdo). "Um dia fomos lá [na APAE] levar o meu filho para a 
professora de Terapia Ocupacional (TO),(...) ela pegou o celular e achei que ela estava atendendo e falando ocupada no celular dela, de repente me mostrou o celular dela e lá estava o sinalizador do ProDeaf sinalizando uma frase comprida e lá eu fiquei quase paralisada é como tivesse um interprete de Libras pronto no celular dela, é interessante porque podemos comunicar melhor de Libras do que escrevendo ou lendo a leitura labial as vezes pode ter entendido mal. (Sujeito Surdo)

Os ganhos de autonomia relatados pelos sujeitos vão ainda além das interações sociais cotidianas. Sujeitos surdos mencionaram benefícios individuais relacionados a elementos constitutivos da intimidade e construção da identidade da pessoa ao utilizar os aplicativos: "Tem frase que é segredo não vou mostrar para ouvinte explicar para mim, o ProDeaf me ajuda" (Sujeito Surdo) ou ainda "Para surdos que tem duvida a palavra de português que poderia usar esse aplicativo que vai traduzir em Libras sem vergonha de pedir alguém o significado da palavra" (Sujeito Surdo). Tais declarações validam a premissa de Lévy (2000) de que o ganho de autonomia das pessoas ou dos grupos envolvidos deve ser o objetivo principal da luta contra as desigualdades e a exclusão. Neste viés, Bakhtin (1990) afirma a importância da linguagem e dos signos na construção da consciência humana, inferindo que é por meio de interações verbais e do estabelecimento de diálogos que o indivíduo desenvolve o pensamento e a consciência. Tais signos podem ser de natureza gestual-visual, como a Libras, e não apenas orais ou gráficos, como em Língua Portuguesa.

\subsection{Conectividade}

A maior parte dos recursos disponíveis nos aplicativos HandTalk e ProDeaf operam apenas quando conectados à Internet, o que pode constituir-se em um impedimento para o desempenho do papel inclusivo desses em contextos escolares, uma vez que muitas escolas brasileiras ainda não possuem acesso à Internet ou não disponibilizam acesso a todos os seus espaços. Esse aspecto se constitui como uma barreira no que tange a utilização online de aplicativos móveis. Logo, a falta de concetividade restringe a principal potencialidade das ferramentas que é permitir a socialização entre surdos e ouvintes nos variados espaços da escola ou da vida cotidiana.

Dados estatísticos nacionais dão conta de que $89 \%$ das escolas públicas brasileiras possuem acesso à Internet. Dessas, apenas 57\% dispõem de conexão sem fio (TIC Educação, 2013). Esse número, entretanto, é menos representativo do que aparenta, visto que em muitas escolas o acesso à Internet fixa ou móvel restringe-se às esferas administrativas, seja por questões técnicas relativas ao equipamento e à qualidade do sinal, seja por posicionamento pedagógico de liberação do acesso a alunos.

Observou-se, nesta categoria, a preponderância de fragmentos discursivos negativos, uma vez que é na mobilidade que os aplicativos demonstram sua principal potencialidade (a de socialização nos mais variados ambientes), dificuldades relacionadas à conexão com a Internet móvel são obstáculos que acabam limitar a validade social dessas ferramentas.

\section{A DINÂMICA QUE CONCRETIZA A VALIDADE SOCIAL DOS APLICATIVOS}

Com base nas categorias mencionadas, elaboramos , ao final da análise realizada, um esquema da dinâmica de utilização dos aplicativos, conforme Fig. 2, na qual as ferramentas HandTalk e ProDeaf dependem de três elementos para que possam ser operados, sendo eles: (a) possuir um smartphone compatível com os sistemas operacionais mencionados na tabela 1, (b) ter acesso à Internet móvel e (c) saber como utilizá-los. Atendendo a esses requisitos, é possível que os aplicativos mediem a 
interação entre pessoas surdas e ouvintes ou, ainda, a interação de pessoas surdas e contextos escritos ou sinalizados, de forma a resultar em uma melhor integração social e linguística.

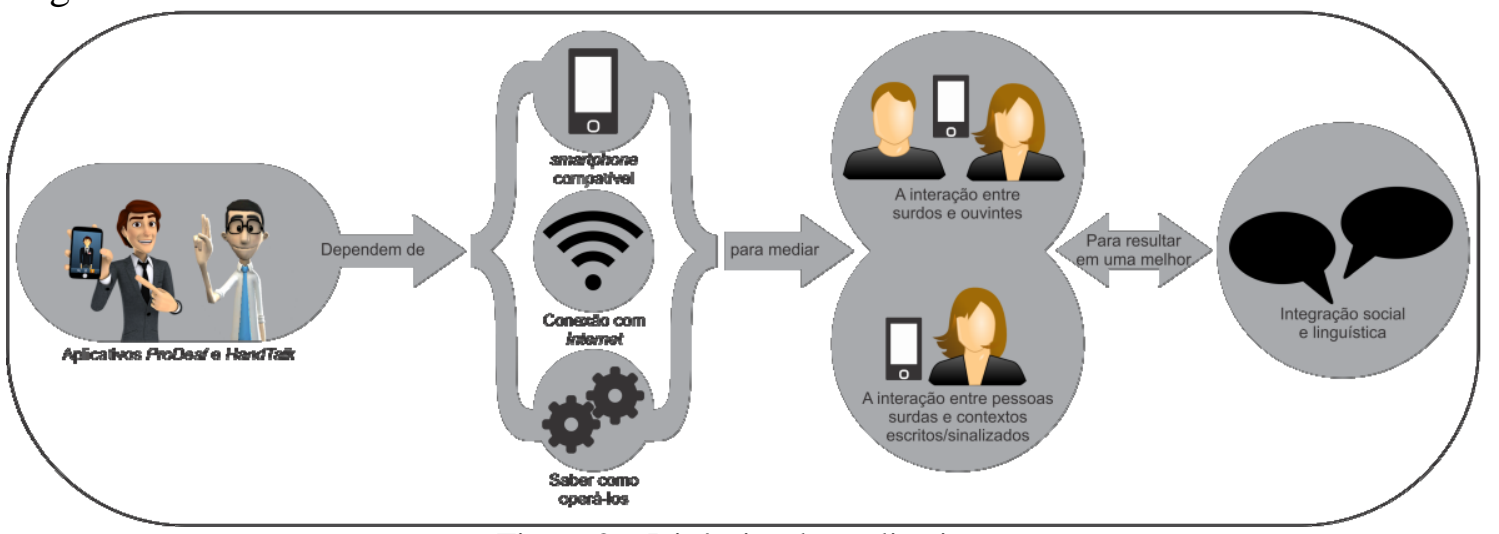

Figura 2 - Dinâmica dos aplicativos

Compreende-se que, diante da dinâmica estrutural do panorama operacional outrora apresentado, os fatores impeditivos para uma efetiva utilização dessas ferramentas, situam-se na esfera econômica, seja no que concerne ao custo individual dos aparelhos smartphones compatíveis e com Internet móvel. Esbarra-se ainda em questões estruturais e filosóficas da educação brasileira, como a situação do acesso à Internet nas escolas: quando existe, nem sempre está disponível para uso entre os estudantes (TIC Educação, 2013).

\section{CONSIDERAÇÕES FINAIS}

Após ter observado a dinâmica de utilização dos aplicativos (Fig. 2), pode-se considerar que os mesmos são capazes de contribuir para a inclusão social da pessoa surda, desde que salvaguardados os três elementos (seção 5) dos quais depende o acesso aos mesmos, uma vez que esses podem representar barreiras para pessoas que não possuam equipamentos compatíveis, acesso à Internet sem fio, ou ainda, que não possuam fluência no uso de tecnologias digitais.

Embora tenham emergido categorias de análise que apontam tanto para aspectos positivos quanto negativos das ferramentas, a totalidade dos sujeitos envolvidos apresentou posicionamentos favoráveis à utilização dos aplicativos, mesmo em situações nas quais foram apontadas fragilidades. Ressalta-se que a incidência de fragmentos discursivos positivos foi superior aos negativos, na proporção de 100 para 33, de um total de 133, o que corrobora a aceitação dessas ferramentas, junto ao universo de sujeitos desta pesquisa.

A análise deflagrou o potencial inclusivo da ferramenta como elemento preponderante, favorecendo processos de socialização (Vygotsky, 2010) e facilitando da interação entre surdos e ouvintes, de modo a amenizar processos de segregação social (Warschauer, 2006), promovendo experiências de escolarização inclusivas (Quadros, 2013). As possibilidades de ampliação do arcabouço linguístico do Português e da Libras, para surdos e ouvintes, da autonomia e a constituição íntima dos sujeitos surdos evidencia que, conforme Bakhtin (1990) e Vygotsky (2010) , a linguagem exerce funções para além da comunicação; sendo ela considerada uma ferramenta de mediação que possibilita ao indivíduo a construção de sua: identidade, intimidade, subjetividade, inserindo-o dentro da ideologia de sua comunidade.

\footnotetext{
${ }^{1}$ Exceto ferramenta de entrada de voz. As demais ferramentas podem ser utilizadas sem acesso à Internet, embora o desempenho seja mais eficiente quando o dispositivo está conectado à Internet.
} 


\footnotetext{
${ }^{2}$ Todas as narrativas apresentadas neste estudo foram mantidas quanto à sua forma e conteúdo, logo, sem quaisquer correções ortográficas, sintáticas ou semânticas. É válido ainda afirmar que a estrutura semântica da escrita de sujeitos surdos, em geral, se difere da Língua Portuguesa padrão.

${ }^{3}$ Aparelho da marca Samsumg, modelo Galaxy Trend.
}

\section{Referências bibliográficas}

BAKHTIN, Mikhail. Marxismo e filosofia da linguagem. Tradução Michel Lahud e Yara Frateschi Vieira. São Paulo: Hucitec, 1990.

BARDIN, L. Análise de conteúdo. Lisboa: Ed. 70, 2007.

BARTH, C., SILVA, A. A., SANTAROSA, L. M. C. Aquisição da Escrita de Sinais por Crianças Surdas através de Ambientes Digitais. RENOTE - Revista Novas

Tecnologias na Educação, v. 5, n. 2, p. 1-12, 2007.

BRASIL. Secretaria de Educação Especial. Política Nacional de Educação Especial na Perspectiva da Educação Inclusiva. MEC/SEESP, 2008.

. Decreto-lei nº.166, de 23 de dezembro de 2013. Diário Oficial [da]

República Federativa do Brasil, Brasília, 24 dez. 2013.

COOK, A.M. e HUSSEY, S. M. Assistive Technologies: Principles and Practices. St. Louis, Missouri. Mosby - Year Book, Inc., 1995.

LÉVY, P. Cibercultura. 2. Ed. São Paulo: Ed. 34, 2000.

MORAES, R.. Uma tempestade de luz: a compreensão possibilitada pela análise textual discursiva. Ciência Educação, Bauru, SP, v. 9, n. 2, p. 191-210, 2003.

NIELSEN, J. Introduction to Usability. Alertbox: Current Issues in Web Usability, 2003. [S.I.:s.n.] Disponível em: <http://www.useit.com/alertbox/20030908.html>. Acesso em maio. 2009.

QUADROS, R. M. de. Situando as diferenças implicadas na educação de surdos: inclusão/exclusão. Ponto de Vista, Florianópolis, n.05, p. 81-111, 2003.

SANTAROSA, L. M. C.; CONFORTO, D. Formação de Professores: Construindo Cenários Inclusivos. RENOTE - Revista Novas Tecnologias na Educação, v. 8, n. 1, 2010.

SANTAROSA, L.M.C e CONFORTO, D. Formação de Professores em Tecnologias Digitais Acessíveis. Porto Alegre: Evangraf, 2012.

TIC Educação 2012. Pesquisa sobre o uso das tecnologias de informação e comunicação no Brasil. São Paulo: Comitê Gestor da Internet no Brasil, 2013.

TOURAINE, A. Pensar outramente o discurso interpretativo dominante. Petrópolis, RJ: Vozes, 2009.

VYGOTSKY, L. S. Pensamento e Linguagem. Rio de Janeiro: Martins Fontes, 1998.

VYGOTSKY, L.S. A formação social da mente. São Paulo: Martins Fontes, $4^{\mathrm{a}}$ ed, 2010.

WARSCHAUER, M. Tecnologia e inclusão social: a exclusão digital em debate. São Paulo: Senac, 319p, 2006.

WERSTCH, J.Vygotsky y la formación social de la mente. Série Cognición y desarrollo humano. Barcelona: Ed. Paidós. 1988. 